\title{
A development in the preparation of sharp scanning tunneling microscopy tips
}

Song, J. P.; Pryds, N. H.; Glejbøl, K.; Mørch, Knud Aage; Thölén, A. R.; Christensen, Lars Nygaard

Published in:

Review of Scientific Instruments

Link to article, DOI:

$10.1063 / 1.1144140$

Publication date:

1993

Document Version

Publisher's PDF, also known as Version of record

Link back to DTU Orbit

Citation (APA):

Song, J. P., Pryds, N. H., Glejbøl, K., Mørch, K. A., Thölén, A. R., \& Christensen, L. N. (1993). A development in the preparation of sharp scanning tunneling microscopy tips. Review of Scientific Instruments, 64(4), 900-903. https://doi.org/10.1063/1.1144140

\section{General rights}

Copyright and moral rights for the publications made accessible in the public portal are retained by the authors and/or other copyright owners and it is a condition of accessing publications that users recognise and abide by the legal requirements associated with these rights.

- Users may download and print one copy of any publication from the public portal for the purpose of private study or research.

- You may not further distribute the material or use it for any profit-making activity or commercial gain

- You may freely distribute the URL identifying the publication in the public portal 


\title{
A development in the preparation of sharp scanning tunneling microscopy tips
}

\author{
J. P. Song ${ }^{\text {a) }}$ \\ Laboratory of Applied Physics and Danish Institute of Fundamental Metrology, Building 307, Technical \\ University of Denmark, DK-2800 Lyngby, Denmark
}

N. H. Pryds, K. Glejbøl, K. A. Mørch, A. R. Thölén, and L. N. Christensen

Laboratory of Applied Physics, Building 307, Technical University of Denmark, DK-2800 Lyngby,

Denmark

(Received 30 September 1992; accepted for publication 24 November 1992)

\begin{abstract}
An improved and reliable method for making sharp scanning tunneling microscopy (STM) tips is described. It is based on the widely used drop-off electrochemical etching procedure, here modified to improve the control of the tip shape. A second etching is applied not only to remove the oxide layer from the tip surface, but also to sharpen the STM tips further. A tip radius less than $20 \mathrm{~nm}$ can be obtained reproducibly. The quality of the produced tips was inspected with transmission electron microscopy, and micrographs of tips produced with different times of second etching are shown. To produce tips which are all without an oxide layer an electronic phase control unit is necessary. Even without this etch controller more than half the tips are oxide free, and then only standard laboratory equipment is used for the tip production.
\end{abstract}

\section{INTRODUCTION}

The quality of scanning tunneling microscopy (STM) tips is one of the important factors which affect the resolution of the STM image or the quality of microlithography. ${ }^{1-3}$ A platinum tip which is cut with a cutter or a razor blade is good enough for observing atomically flat surfaces of samples from highly oriented pyrolytic graphite, silicon etc. Actually, a cut platinum tip is very blunt, but its surface is highly jagged with very small individual protrusions one of which may act as a well defined minitip. ${ }^{4}$ It is believed that there might be one atom at the apex of such a minitip which forms a stable point of tunneling on almost planar surfaces.

However, in many cases when a rough surface is to be investigated over a large scanning range, or for lithography on the surface of a silicon chip, atomic resolution is not necessary, but the sharpness and the geometry of the tip are important factors, which affect the resolution of topographic STM images and the quality of microlithography.

Sharp STM tips are typically fabricated from metal wires of tungsten or platinum-iridium by the drop-off electrochemical etching method. ${ }^{5-9}$ The basic idea of the method is that when the lower part of the etched wire drops off the etching current through the tip is cut off as soon as possible to prevent it from blunting the tip. In Fasth et al. ${ }^{5}$ a second-etching, called backpolishing, was used to smoothen the surface and to control the oxide layer. In the present paper a second-etching is applied during a controlled time not only to remove the oxide layer from the tip surface but also to sharpen the tip further. The tip shape is controlled by shielding part of the metal wire in the electrolyte. This method of tip production is simple, reliable, and fast. The tips were inspected with transmis-

a) On leave from Dept. of Electronic Engineering, Xi'an Jiaotong University, P.R. China. sion electron microscopy (TEM) in high magnification for control of their shape and quality.

\section{SETUP AND METHOD OF TIP PREPARATION}

Our experimental setup is schematically shown in Fig. 1. A tungsten wire of diameter $0.5 \mathrm{~mm}$ is used as the tip material and it traverses a layer of electrolyte $(E)$, a 1-M $\mathrm{NaOH}$ solution at room temperature, floating on a nonconducting fluid $(N), \mathrm{CCl}_{4}$. A platinum foil $(P)$ mounted on the electrode-connection $E 1$ and bent to form a spring of small stiffness is immersed in the liquid $N$ where it touches the lower part of the tungsten wire and makes it act as electrode. The second electrode, $E 2$, is made from $0.5-\mathrm{mm}$ platinum wire formed as a circular loop of diameter $40 \mathrm{~mm}$ and placed in the electrolyte with the tungsten wire passing through the loop center. The tungsten wire is partly shielded from the electrolyte by two small plastic tubes, $T 1$ which fits to the wire and $T 2$ which fits to the outer diameter of $T 1$. They prevent the wire from being exposed to the full layer of electrolyte which has a thickness of 3-6 $\mathrm{mm}$. The tube dimensions and the distance $d$ between $T 2$ and the interface of the two liquids ( $E$ and $N$ ) can be changed for control of the aspect ratio (length/ diameter) of the tip as required for different applications.

Each tip is made by electrochemical etching in two steps. In the first step the tungsten wire is etched until it breaks into two halves by applying a $50-\mathrm{Hz}$ voltage of $5-10$ $\mathrm{V}$ (rms) to the electrodes $E 1$ and $E 2$. This leads to an etching current of $200-600 \mathrm{~mA}$, the value depending on the distance $d$. When the wire breaks the lower part of the tungsten wire drops into the liquid $N$. Hereby the current is switched off in a fast and highly reproducible way. The distance $d$ can be easily controlled and the basic tip shape obtained in this first etching is also highly reproducible. In Fig. 2 examples of such tips produced with and without the 


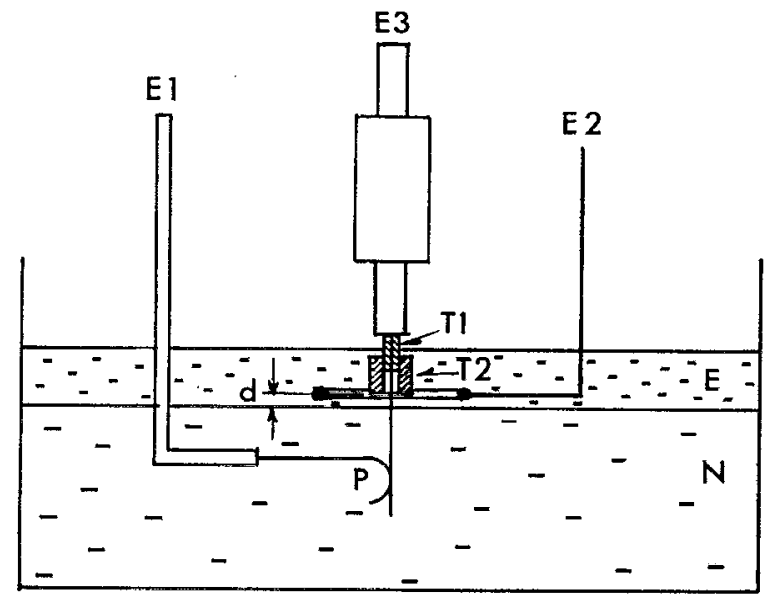

FIG. 1. Experimental setup for electrochemical preparation of sharp tips.

plastic tubes are shown. It is apparent that the tubes effectively protect the upper part of the wire in the electrolyte.

In the next step of the tip fabrication, a second etching is used. Now the upper part of the tungsten wire $E 3$ and the platinum loop $E 2$ serve as the electrodes, and they are connected to an etch controller (built in our laboratory) which allows the etching time and the current cut-off phase to be controlled. The tip is second-etched also at $5 \mathrm{~V}$ $(\mathrm{rms}), 50 \mathrm{~Hz}$. The voltage on the tungsten wire $(E 3)$ is switched off after an appropriately chosen time and at the moment when it reaches its extremum value in the negative phase (relative to the potential of the platinum electrode). Immediately afterwards the electrode $E 3$ is disconnected from the electric circuit. In this process a very sharp tip without an oxide layer is produced. The technique gives highly reproducible results. If the etch controller (which is the only specialized equipment used in the tip production) is not available the second-etching can be carried out by connecting and breaking the etch circuit by hand. Then, statistically the current is broken in correct phase for about half the tips, and a reasonable percentage of them are oxide free and thus applicable for STM.

\section{RESULTS AND DISCUSSION}

To obtain oxide-free tips it is important that the ac frequency used in second-etching is not too high. In our
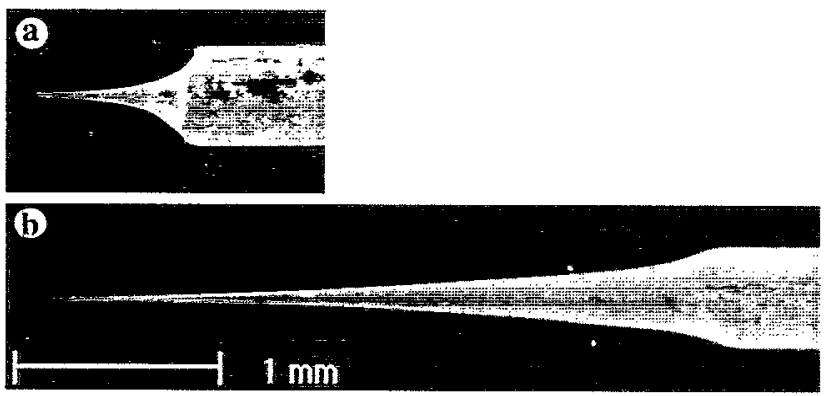

FIG. 2. (a) Tungsten tip produced with the use of shielding tubes at $d \approx 1$ $\mathrm{mm}$. (b) Tip produced without shielding tubes in an approximately 4-mm-thick layer of electrolyte.

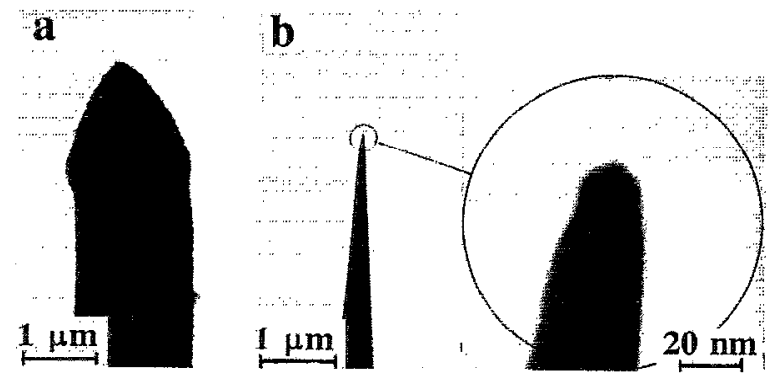

FIG. 3. TEM micrographs of the apex of the same tungsten tip (a) after a first-etching without shielding tubes at $50-\mathrm{Hz}$ ac voltage of $7 \mathrm{~V}$ (rms) and (b) after a second-etching at $50-\mathrm{Hz}$ ac voltage at $7 \mathrm{~V}$ (rms) for about $1 \mathrm{~s}$ and cut-off in the negative phase at extremum voltage.

initial experiments $1000 \mathrm{~Hz}$ was used resulting in tips covered by a thin layer of oxide. By reducing the frequency to $500-\mathrm{Hz}$ oxide-frce tips were obtained. The results were equally satisfactory at lower frequencies. Therefore, it was chosen to use $50 \mathrm{~Hz}$. We assume that the demand for a frequency below a certain limit is connected to the limited mobility of the $\mathrm{WO}_{4}^{2-}$ ions in the electrolyte, where they have to move away from the tip surface.

A Philips 430 electron microscope working at $300 \mathrm{kV}$ was used to study the tips. They are placed in a specially built side-entry holder, which allows rotation around the tip axis. Figure 3 (a) shows a micrograph of a tip after firstetching without use of the plastic tubes $T 1$ and $T 2$, and in Fig. 3(b) the same tip is shown after the second-etching. It is evident that the tip is much sharper after the secondetching. The radius of curvature of this tip is only $10 \mathrm{~nm}$ as seen in the high magnification inset.

The time of second-etching is a variable which can be chosen with the etch controller while other parameters are kept at fixed values. Figures 4(a)-4(d) show TEM images of four tips for which the second-etching times are 0.5, 0.7, $1.0,1.3 \mathrm{~s}$, respectively, at a current of about $200 \mathrm{~mA}$. It is found that with a second-etching timc of $0.7-1.0 \mathrm{~s}$ the sharpest tips are obtained. At prolonged second-etching the sharpness again decreases. (If other parameters for the etching system are chosen, other optimum times of secondetching may be found.)

It is important to notice that in the second-etching not only the voltage between $E 3$ and $E 2$ has to be cut off on correct time and in the right phase, but the tip must also be disconnected from the circuit as soon as possible. It is illustrated by an experiment in which we disconnected all wires from $E 1, E 2$, and $E 3$ and put the tip which is shown in Fig. 4(c) back into the tip holder of $E 3$, inserted it in the $\mathrm{NaOH}$ solution again and connected $E 2$ and $E 3$ through a $1-\mathrm{k} \Omega$ resistor for $2 \mathrm{~min}$. The system acts as a battery with a voltage of about $-500 \mathrm{mV}$ on tungsten with respect to platinum, and accordingly the tip is etched when $E 2$ and $E 3$ are connected. The tip was observed again in TEM and had changed as shown in Fig. 5. It became blunt and misshaped.

To avoid unwanted charge transport due to the electrochemical potentials our etching circuit is designed so 


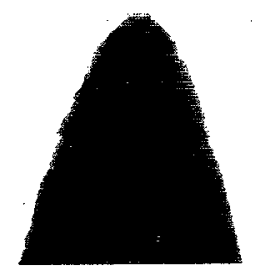

c

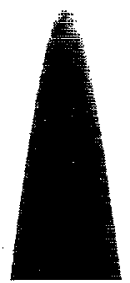

b

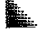

d

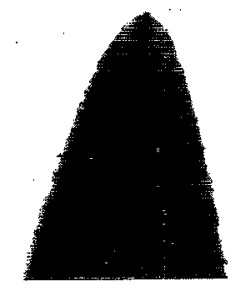

FIG. 4. TEM images of four different tungsten tips which were firstetched by an ac voltage of $5 \mathrm{~V}$ (rms) and a current of $200 \mathrm{~mA}$, followed by a second-etching for (a) $0.5 \mathrm{~s}$, (b) $0.7 \mathrm{~s}$, (c) $1.0 \mathrm{~s}$, and (d) $1.3 \mathrm{~s}$.

that when the second-etching procedure is activated a relay connects $E 3$ to the power supply within $2 \mathrm{~ms}$ and after the preset second-etching time has passed, $E 3$ is again disconnected within $2 \mathrm{~ms}$. With this method the quality of the produced tips is improved as demonstrated in Figs. 4(a)$4(d)$.

Using the method of low-current second etching it is easy to make sharp tips with a tip radius below $20 \mathrm{~nm}$ in a highly reproducible way. The reason for the secondetching sharpening the tips instead of blunting them may be that when $E 3$ is totally disconnected from the circuit the positively charged ions in the electrolyte build up a space charge surrounding the tip. At the apex of the tip the electric field is stronger than at the conical shaft. There-

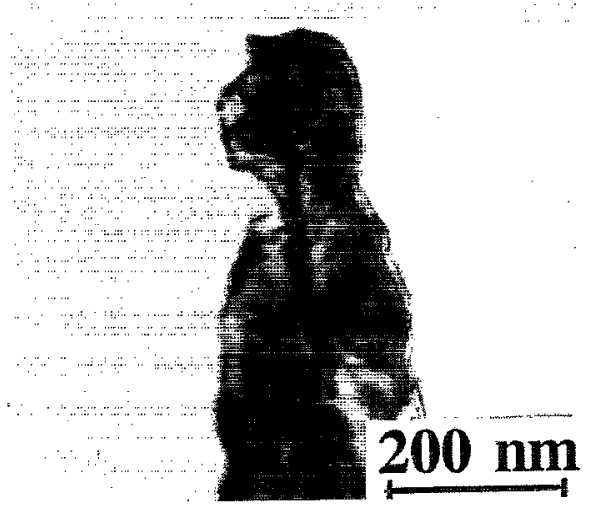

FIG. 5. TEM image of the tip shown in Fig. 4(c) after it was again placed in tip holder $E 3$, inserted in the $\mathrm{NaOH}$ solution and connection was made through a $1-\mathrm{k} \Omega$ resistor between $E 2$ and $E 3$ for 2 min. The tip is spoiled by uncontrolled etching caused by the electrochemical potentials. fore, the positive space charge which is built up around it is more dense here. When the second-etching is initiated the space charge at the apex shields it better than it shields the shaft. Accordingly, during a short interval of time the shaft is etched stronger than the apex, and the tip is sharpened. If etching is continued beyond this interval of time the apex is strongly etched and the tip becomes more blunt again.

When using a high etching current, $600 \mathrm{~mA}$, a small sphere of tungsten is usually formed at the very tip after the first-etching, while no sphere is observed at low etching currents. The origin of the sphere is expected to be the very localized heating of the wire just when it breaks into two halves. Just before this moment the current runs through the extremely thin link between the upper and lower wire parts giving rise to local melting. The formation of the sphere may be exploited in the second-etching to ensure that a very small protrusion forms the very tip. The sphere is believed to be removed from the tip during secondetching as it is gradually thinned and the mechanical stress in the connection between the tip and the sphere finally exceeds the fracture stress of the material which deforms
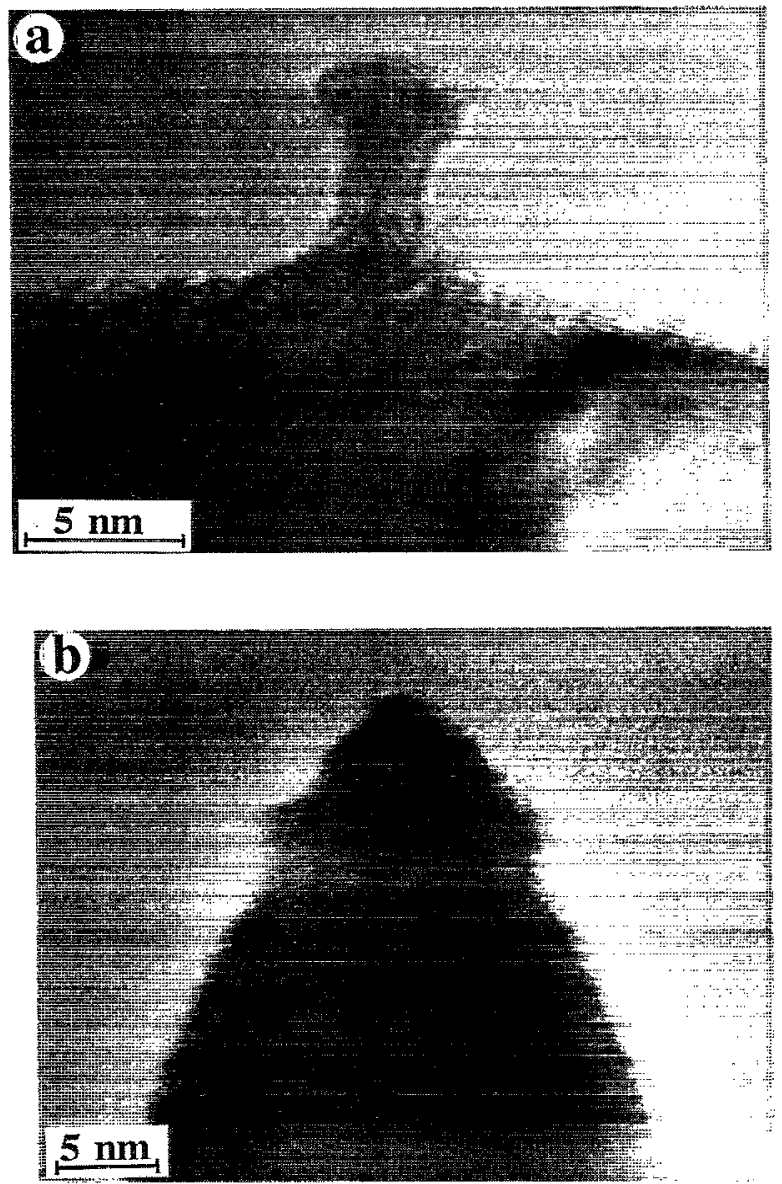

FIG. 6. (a) Transmission electron micrograph of a tungsten tip first etched at $600 \mathrm{~mA}$ and then second etched for about $1 \mathrm{~s}$, whereby a small protrusion is left on the tip. (b) A similar tip after being second etched once more for a few ms. The (110) planes are visible in both tips and reach right to the tip surface, thus demonstrating that the tips are oxide free. The lattice constant of tungsten is $0.224 \mathrm{~nm}$. 
and breaks forming the small surface protrusion. After this moment the second-etching should be stopped, but the precise time does not seem important. Evidence for this behavior is found in numerous micrographs of tips with protrusions of size only a few nanometers. An example is shown in Fig. 6(a). Second-etching once more for just a few milliseconds at $500 \mathrm{~Hz}$ removes the protrusion and may sharpen the tip significantly. An example is shown in Fig. 6(b).

\section{ACKNOWLEDGMENTS}

The authors wish to thank Mr. A. Henschel for assistance with TEM. The Daloon Foundation is thanked for financial support to J. P. Song. K. Glejbøl is financed by the Centre for Surface Technology as part of the Danish Materials Research Programme.
${ }^{1}$ E. Stoll, Surf. Sci. 143, L411 ( 1984).

${ }^{2}$ L. Madsen, B. N. Zaba, M. v. d. Sluijs, A. E. Underhill, and K. Carneiro, J. Mater. Chem. 1, 503 (1991).

${ }^{3}$ M. A. McCord and R. F. W. Pease, J. Vac. Sci. Technol. B 6, 293 (1988).

${ }^{4}$ J. Garnæs, F. Kragh, K. A. Mørch, and A. R. Thölén, J. Vac. Sci. Technol. A 8, 441 (1990).

${ }^{5}$ J. E. Fasth, B. Loberg, and H. Nordén, J. Sci. Instrum. 44, 1044 (1967).

${ }^{6}$ P. J. Bryant, H. S. Kim, Y. C. Zheng, and R. Yang, Rev. Sci. Instrum. 58, 1115 (1987).

${ }^{7}$ J. P. Ibe, P. P. Bey, Jr., S. L. Brandow, R. A. Brizzolara, N. A. Burnham, D. P. DiLella, K. P. Lee, C. R. K. Marrian, and R. J. Colton, J. Vac. Scí. Technol. A 8, 3570 (1990).

${ }^{8}$ H. Lemke, T. Göddenhenrich, H. P. Bochem, U. Hartmann, and C. Heiden, Rev. Sci. Instrum. 61, 2538 (1990).

${ }^{9}$ K. Glejbøl, N. N. Hamawi, and A. R. Thölén, Micron and Microscopica Acta 22, 125 (1991). 